\title{
Estimating and projecting HIV prevalence and AIDS deaths in Tanzania using antenatal surveillance data
} Geofrey R Somi ${ }^{1}$, Mecky IN Matee*2, Roland O Swai ${ }^{1}$, Eligius F Lyamuya ${ }^{2}$, Japhet Killewo ${ }^{2}$, Gideon Kwesigabo ${ }^{2}$, Tuhuma Tulli ${ }^{1}$, Titus K Kabalimu ${ }^{3}$, Lucy Ng'ang' ${ }^{4}$, Raphael Isingo ${ }^{5}$ and Joel Ndayongeje ${ }^{1}$

\author{
Address: ${ }^{1}$ National AIDS Control Programme, Dar es Salaam, Tanzania, ${ }^{2}$ Muhimbili, University College of Health Sciences, Dar es Salaam \\ Tanzania, ${ }^{3}$ Commission for Science and Technology, Dar es Salaam, Tanzania, ${ }^{4}$ Centres for Disease Control-Tanzania AIDS, Dar es Salaam, \\ Programme, Tanzania and ${ }^{5}$ National Institute for Medical Research, Dar es Salaam, Tanzania \\ Email: Geofrey R Somi - G_somi@yahoo.co.uk; Mecky IN Matee* - mmatee@muchs.ac.tz; Roland O Swai - swairo@nacptz.org; \\ Eligius F Lyamuya - elyamuya@muchs.ac.tz; Japhet Killewo - Jkillewo@muchs.ac.tz; Gideon Kwesigabo - Gkwesigabo@muchs.ac.tz; \\ Tuhuma Tulli - tuhumat@yahoo.com; Titus K Kabalimu - tkabalimu@costech.or.tz; Lucy Ng'ang'a - ngangal@tz.cdc.gov; \\ Raphael Isingo - rrisingo@yahoo.co.uk; Joel Ndayongeje - ndayongeje@nacptz.org \\ * Corresponding author
}

\section{Published: 03 May 2006}

BMC Public Health 2006, 6:120 doi:10.1 I86/147|-2458-6-120
Received: 07 September 2005

Accepted: 03 May 2006

This article is available from: http://www.biomedcentral.com/I47I-2458/6/I20

(c) 2006 Somi et al; licensee BioMed Central Ltd.

This is an Open Access article distributed under the terms of the Creative Commons Attribution License (http://creativecommons.org/licenses/by/2.0), which permits unrestricted use, distribution, and reproduction in any medium, provided the original work is properly cited.

\begin{abstract}
Background: The Estimations and Projections Package (EPP 2005) for HIVIAIDS estimates and projects HIV prevalence, number of people living with HIV and new HIV infections and AIDS cases using antenatal clinic (ANC) surveillance data. The prevalence projection produced by EPP can be transferred to SPECTRUM, a demographic projection model, to calculate the number of AIDS deaths. This paper presents estimates and projections of HIV prevalence, new cases of HIV infections and AIDS deaths in Tanzania between 200I and 2010 using the EPP 2005 and SPECTRUM soft-wares on ANC data.

Methods: For this study we used; the $1985-2004$ ANC data set, the 2005 UN population estimates for urban and rural adults, which is based on the 2002 population census, and results of the 2003 Tanzania HIV Indicator Survey. The ANC surveillance sites were categorized into urban and rural areas on the basis of the standard national definitions of urban and rural areas, which led to 40 urban and 35 rural clinic sites. The rural and urban epidemics were run independently by fitting the model to all data and on level fits.

Results: The national HIV prevalence increased from $0 \%$ in 1981 to a peak of $8.1 \%$ in 1995 , and gradually decreased to $6.5 \%$ in 2004 which stabilized until 2010. The urban HIV epidemic increased from $0 \%$ in 1981 peaking at $12.6 \%$ in 1992 and leveled to between $10.9 \%$ and $11.8 \%$ from 2003 to 2010 . The rural epidemic peaked in 1995 at $7.0 \%$ and gradually declined to $5.2 \%$ in 2004 , and then stabilized at between $5.1 \%$ and $5.3 \%$ from 2005 to 2010 . New infections are projected to rise steadily, resulting in 250,000 new cases in 20I0. Deaths due to AIDS started in 1985 and rose steadily to reach 120,000 deaths in 2010 , with more females dying than men.

Conclusion: The fact that the number of new infections is projected to increase steadily to reach 250,000 per year in 2010 calls for more concerted efforts to combat the spread of HIV infection particularly in the rural areas where the infrastructure needed for prevention programmes such as counseling and testing, condom accessibility and AIDS information is less developed.
\end{abstract}




\section{Background}

Recently, the World Health Organization (WHO), the joint united nation programme on HIV/AIDS (UNAIDS) and their partners released an updated software, the Estimations and Projections Package (EPP 2005) for HIV/ AIDS [1], to estimate and project adult HIV prevalence in countries with heterosexual epidemics of HIV infection. The input to EPP is surveillance data from various sites and years showing HIV prevalence among pregnant women. The assumption is that, in these countries, HIV prevalence in pregnant women attending antenatal clinics (ANCs) is taken to represent prevalence in all adults, male and female, aged 15-49. This key assumption is based on the comparison in a large numberof studies of HIV prevalence among pregnant women and in communitysurveys among all men and women aged 15-49 [2-9].

Usually, the dynamics of national HIV epidemics are complex and almost all HIV epidemics consist of multiple subepidemics. These sub-epidemics may affect different subpopulations, occur with different timing and severity in different geographical areas, and usually evolveat different rates. Modelling the dynamics of many complex national epidemics realistically requires the ability to model the individual sub-epidemics of which they are composed. For countries that have recently conducted national community based surveys, the UNAIDS Reference Group on Estimates, Modelling and Projections recommends the use of national survey derived HIV prevalence estimates to calibrate the HIV prevalence level in the EPP [1]. This should bedone separately for urban and rural areas and, if the information is available, also by geographical regions. The prevalence projection produced by EPP can be transferred to SPECTRUM to calculate AIDS deaths [10]. We used EPP and SPECTRUM soft-wares to estimate and project HIV prevalence, number of new cases of HIV infection and AIDS deaths in Tanzania for the period ranging from 1980 to 2010 using available ANC prevalence data.

\section{Methods \\ The EPP model}

The UNAIDS/WHO Estimation and Projection Package (EPP) uses available surveillance data to estimate the time trend of adult prevalence of HIV-1 at the national level. EPP can be used for either concentrated epidemics (regarded as such if HIV infection has spread rapidly in at least one defined sub-population, but is not well-established in the general population. HIV prevalence is consistently over $5 \%$ in at least one defined subpopulation but below $1 \%$ in pregnant women in urban areas) or generalized epidemics (regarded as such if HIV infection is firmly established in the general population and HIV prevalence is consistently over $1 \%$ in pregnant women).
EPP estimates the time trend of HIV prevalence by fitting a simple epidemiological model to the surveillance data provided by HIV sentinel surveillance systems.

National HIV epidemics are usually composed of multiple epidemics in different populations and different geographic areas. To reflect this, one of the fundamental principles underlying EPP is that epidemic curves can be developed separately for different populations and then combined to produce a single epidemic curve which estimates HIV prevalence at a national level. There is no limit to the number of sub-national epidemic curves you can create as long as sufficient data exists to fit a curve for each sub-population. In generalized heterosexual epidemics the normal way to divide the populations for modelling is by geographic subdivisions such as urban and rural regions or national sub-regions such as provinces or states. Separate estimates and time trends are developed for each of these geographical units, and they are then combined within EPP to produce a national estimate for HIV prevalence and its trends over time.

In developing the approach to be used in fitting, the UN Reference group on Estimates, Modelling and Projections http://www.epidem.org has determined that a model with four parameters is well suited to fitting HIV epidemic curves. The shape of the resulting epidemic curve and the influences of these four parameters are discussed in more detail in articles available at http://www.epidem.org/pub lications.htm.

Briefly the four parameters are; t0 - the start year of the HIV/AIDS epidemic, $r$ - the force of infection. A large value of $r$ will cause prevalence to increase rapidly while a small value will cause it to increase slowly. F0, a parameter representing the initial fraction of the adult population at risk, determines the peak level of the epidemic curve. Phithe behaviour adjustment parameter determines how the proportion of new entrants in the adult population who are at risk changes over time. If phi is negative, people reduce their risk in response to the epidemic and the curve shows a sharper decline after peak. If phi is zero, the proportion at risk remains constant and the prevalence decline after the peak as people die. If phi positive, risk actually increases over time and prevalence falls less quickly or stabilizes at a high level.

\section{Spectrum}

Spectrum is a modular program that is used to examine the consequences of current trends and future program interventions in reproductive health. The core of Spectrum is a demographic projection model, called DemProj that projects the population by age and sex. Other modules interact with the demographic projection. They can 
be used as required. These modules address a variety of issues including impacts of HIV/AIDS (AIDS Impact Model;AIM), resource allocation for HIV/AIDS programs (Goals), the cost effectiveness of programs to prevent mother to child transmission of HIV (PMTCT), options in family planning programs (FamPlan), adolescent reproductive health (NewGen), and the consequences of high fertility and rapid population growth (RAPID). It contains a database of population information that providesinstant access to the population estimates and projections of the United Nations Population Division for all countries andregions of the world. The program and manuals can bedownloaded from the Futures Group website at http:// www.FuturesGroup.com. In this study data from the EPP model was transferred to the spectrum for calculations of deaths arising from AIDS.

\section{The ANC data}

The HIV prevalence data set from ANC clinics covering the period from 1985 to 2002 was agreed upon in a consensus workshop held in Tanzania in 2004 to be used for future estimations and projections. The data set was updated by incorporating the HIV prevalence data from ANC clinics for 2003/2004. A new work set for the current estimates was then created in the EPP 2005 software. In this work set a generalized epidemic state was selected and the national epidemic was defined as urban and rural sub-epidemics. The population was divided into those urban and rural areas in the proportions of $77.4 \%$ for rural and $22.6 \%$ for urban areas based on the 2002 national population census [11]. The rural, urban and total adult populations in Tanzania are shown in Figure 1.

\section{The ANC surveillance sites}

The ANC surveillance sites were categorized into urban and rural areas on the basis of the standard national definitions of urban and rural areas. This definition led to the total number of sites being stratified into 40 urban and 35 rural clinic sites.

\section{Data processing}

HIV Prevalence data of ANC attendees was available from 1986 to 2003 and were entered into the EPP 2005 urban and rural pages. The to, fo, $r$ and $\phi$ were all not fixed to allow the engine to search for the best curve fit. As recommended by the UNAIDS Reference Group on Estimates, Modelling and Projections the ANC HIV prevalence was calibrated using results of the population survey carried in 2003 that showed HIV prevalence to be 5.3\% for rural and $10.9 \%$ for urban areas [12]. The ANC prevalence estimates during the same period for urban, peri-urban, rural and rural/peri-urban (a combination of rural and peri-urban) populations were $11.2 \%, 6.5 \%, .3 .7 \%$ and $5.2 \%$, respectively.

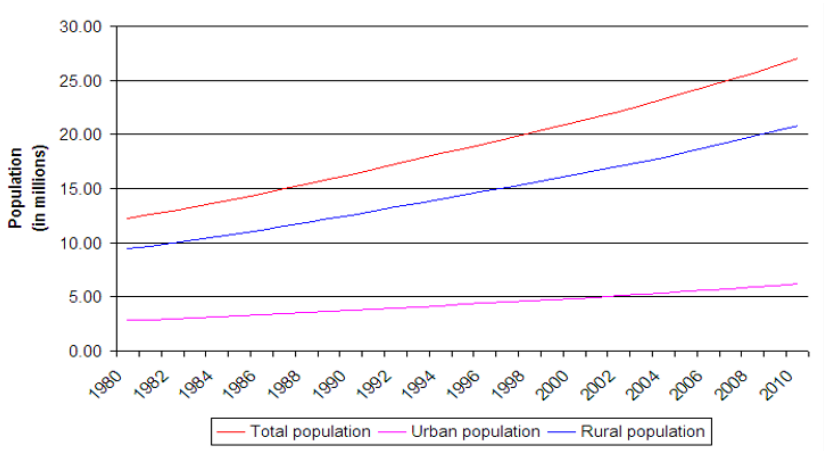

Figure I

Estimates and projections of rural, urban and total adult Tanzania populations from 1980 to 2010 .

Since rural clinics include peri-urban sites, it is evident that they are not truly rural; the UNAIDS Reference Group has recommends HIV seroprevalence values from these rural sites be adjusted to 0.8 of their original value [2], to adjust for the inflating effect of peri-urban sites where HIV prevalence tends to be higher [13-19]. Deaths due to AIDS were calculated using SPECTRUM [10].

\section{Results}

Figure 2 depicts estimates and projections of HIV prevalence for the whole country as well as for urban and rural sub-populations covering the period from 1980 to 2010. The urban curve shows an increasing HIV prevalence from $0 \%$ in 1981 to a peak of $12.6 \%$ in 1992 and subsequently leveled to a plateau between $10.9 \%$ and $11.8 \%$ during the years from 2003 to 2010. The rural curve shows a steeply increasing HIV prevalence trend until 1995 when it reached its peak at $7.0 \%$ that was subsequently followed by a gradual decline to reach $5.2 \%$ in 2004 , and then sta-

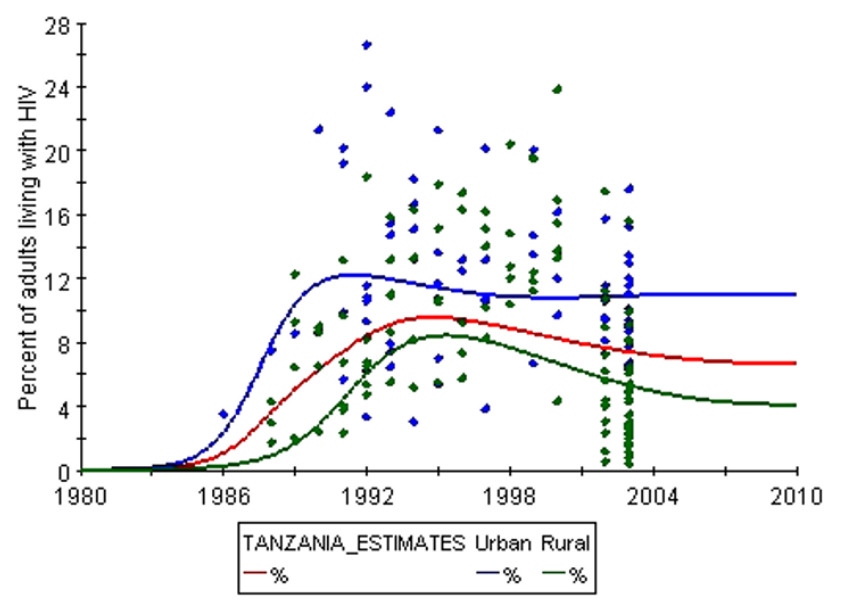

\section{Figure 2}

Estimates and projections of HIV infection among adult Tanzanians from 1980 to 2010 . 
bilizing at between 5.1\% and 5.3\% from 2005 to 2010 . Fig 3 shows the estimates and projections of new HIV infections from 1980 to 2010. According to this figure, new infections rose to peak of 250,000 infections per year in 1995 , before declining to 140,000 in 1997 , and then steadily rising again to 225,000 new infections in 2010 . Between 1983 and 1990 the number of new infections in urban areas was higher than that of rural areas. Since 1991 more new infections are encountered in rural areas, and according to estimates and projections, the absolute number of new HIV infections in rural areas will remain higher and reach twice that of urban areas in 2010 i.e 150, 000 versus 70,000. AIDS deaths started in 1985 and increased steadily to reach 120,000 in 2010 , with more females dying than males (Fig 4).

\section{Discussion}

This study presents estimates and projections of HIV infection and AIDS deaths in Tanzania, as well as for the urban and rural sub-populations for the period ranging from 1980 to 2010 (Fig 2 and 3) and AIDS deaths (Fig 4) using the EPP 2005 software [1] and the SPECTRUM [10].

There are several limitations in the EPP that need to be highlighted. One such limitation is related to the qualityand non-representative nature of data available at present. Rural data areoften not very representative of rural populations, and theEPP by itself cannot resolve this problem. We tried to minimize this bias by lowering the HIV prevalence of rural population by a factor of $20 \%$ as recommended by the UNAIDS Reference Group [1]. Furthermore, the current version of the EPP, for all its sophistication, is still only a curve fitter. It takes the data points provided and adjusts the four parameters $\left(t_{0}, r, f_{0}\right.$ and $\phi$ ) to find single fixed values of those parameters that fit the observed data. This does not allow it to deal with

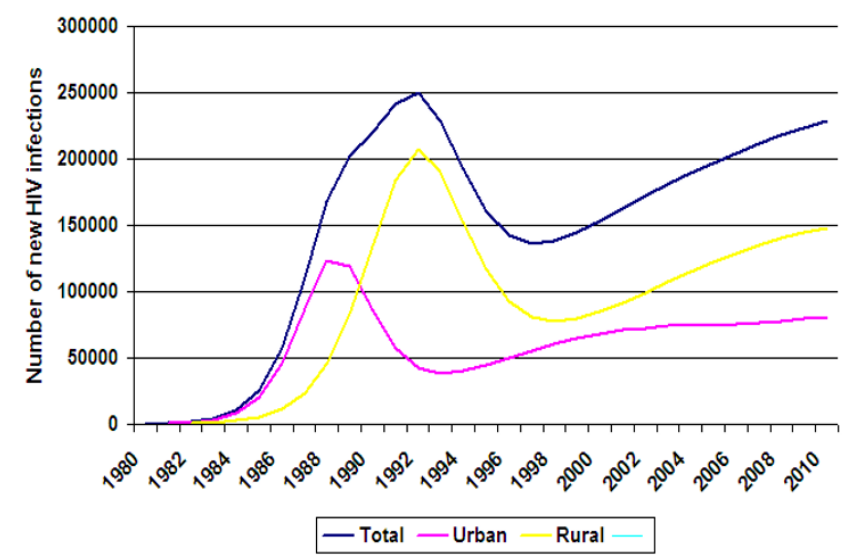

\section{Figure 3}

Estimates and projections of new cases of HIV infection among adult Tanzanians from 1980 to 2010 . issues such as behavioural change in response to interventions (for example increased condom use, decreases in STIs due to improved treatment, and changes in the size ofthe at-risk population as a result of vaccine introduction). Moreover, the choice of values of the four parameters in EPP is dependent on the user's understanding of the epidemic in the country, and may, therefore not necessarily be the best representation of the local epidemic. At present, the EPP can give no estimates of the uncertainty associated with model fits, nor can it estimate high and low future scenarios for the HIV epidemic based on the parameters fit. Finally, as currently implemented, the EPP only allows exit from populations through mortality. Thus, users must be cautioned against taking the model too literally.

The overall national HIV estimates, which represent an average of the rural and urban populations, depict a rise, fall and eventually stabilization of HIV prevalence, which is a natural occurrence due to mortality lagging behind initial infection by years.

When comparing the urban and rural data we found that the urban HIV prevalence peaked at $12.6 \%$ in 1992 and subsequently leveled to a plateau at around $11 \%$ while the rural HIV prevalence peaked three years later in 1995 at 7.0 and then stabilizing at around 5.2\% (Fig 2). The gap between rural and urban areas does not appear to be decreasing and, according to projections, it will remain at $6 \%$.

With regard to new HIV infections, between 1983 and 1990 the number of infections in urban areas was higher than that of rural areas. Since 1991 more new infections are encountered in rural areas, and according to estimates and projections, the absolute number of new HIV infec-

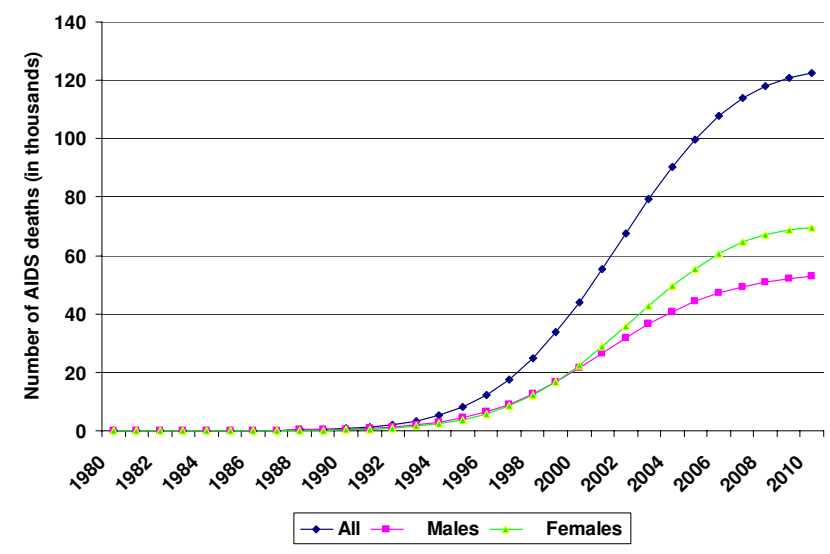

Figure 4

Estimates and projections of AIDS deaths among adult Tanzanians from 1980 to 2010 . 
tions in rural areas will remain higher and reach twice that of urban areas in 2010 i.e 150,000 versus 70,000. The larger absolute numbers of new infections in rural areas is due to the fact that majority $(77 \%)$ of Tanzanians live in these areas. The spread of HIV infection in the rural areas needs special attention given the fact that the infrastructure needed for prevention programmes such as counselling and testing, condom accessibility and AIDS information is less developed [20]. Two types of rural areas that are particularly vulnerable to HIV are recognized as those along truck routes and those that are in areas bordering other countries, an observation which has been linked with community factors such as the level of trade, social and economic activity [21], and ratio of bar workers per male population and level of community mobility [22].

Finally, it is important to note a rise in AIDS deaths that is projected to reach 120,000 deaths per year in 2010, and that more than half of these deaths (58.3\%) will occur among women.

\section{Conclusion}

The fact that the number of new infections is projected to increase steadily to reach 250,000 per year in 2010 calls for more concerted efforts to combat the spread of HIV infection particularly in the rural areas where the infrastructure needed for prevention programmes such as counselling and testing, condom accessibility and AIDS information is less developed. Two types of rural areas that are particularly vulnerable to HIV are recognized as those along truck routes and those that are in areas bordering other countries.

\section{Competing interests}

The author(s) declare that they have no competing interests.

\section{Authors' contributions}

RS and GS designed the study and together with TT and NJ their supervised the field work. RI and JN performed the statistical analyses. GS, EFL and MIM prepared the draft manuscript with assistance from all authors. Finally, all authors read and approved the final manuscript.

\section{Acknowledgements}

We wish to acknowledge with sincere gratitude all those who contributed in this survey. Our thanks go to all health care providers at the regional, district and health care facility levels who have given so earnestly of their time and energy. Their contributions made this report possible. We acknowledge with special gratitude the financial contributions provided by the international partners. These include the US Centres for Disease Control and Prevention (CDC), Joint United Nations Programme on AIDS (UNAIDS), World Health Organisation (WHO) and United Nations Development Project (UNDP). We specifically wish to thank the CDC for their technical collaboration

\section{References}

I. Ghys PD, Brown T, Grassly NC, Garnett G, Stanecki KA, Stover J, Walker N: The UNAIDS Estimation and Projection Package: a software package to estimate and project national HIV epidemics. Sex Transm Infect 2004, 80:5-9.

2. Gregson S, Terceira N, Kakowa M, Mason PR, Anderson RM, Chandiwana SK, Carael M: Study of bias in antenatal clinic HIV-I surveillance data in high contraceptive prevalence populations in sub-Saharan Africa. AIDS 2002, 16:643-652.

3. Fylkesnes K, Ndhlovu Z, Kasumba K, Musonda RM, Sichone M: Studying dynamics of the HIV epidemic: population-based data compared with sentinel surveillance in Zambia. AIDS 1998, I 2:1227-1234.

4. Kilian AH, Gregson S, Ndyanabangi B, Walusaga K, Kipp W, Sahlmuller G, Garnett GP, Asiimwe-Okiror G, Kabagambe G, Weis P, von Sonnenburg F: Reductions in risk behaviour provide the most consistent explanation for declining HIV-I prevalence in Uganda. AIDS 1999, I 3:391-398.

5. Kwesigabo G, Killewo JZ, Urassa W, Mbena E, Mhalu F, Lugalla JL, Godoy C, Biberfeld G, Emmelin M, Wall S, Sandstrom A: Monitoring of HIV-I infection prevalence and trends in the general population using pregnant women as a sentinel population: 9 years experience from the Kegera region of Tanzania. J Acquir Immune Defic Syndr 2000, 23:410-4I7.

6. Ministry of Health: Population-based serosurvey. Kigali: Ministry of Health, Republic of Rwanda. Republic of Rwanda 1997 1998.

7. Kigadye RM, Klokke A, Nicoll A, Nyamuryekung'e KM, Borgdorff M, Barongo L, Laukamm-Josten U, Lisekie F, Grosskurth H, Kigadye F: Sentinel surveillance for HIV-I among pregnant women in a developing country: 3 years' experience and comparison with a population serosurvey. AIDS 1993, 7:849-855.

8. Borgdorff M, Barongo L, van Jaarsveld E, Klokke A, Senkoro K, Newell J, Nicoll A, Mosha F, Grosskurth H, Swai R: Sentinel surveillance for HIV-I infection: how representative are blood donors, outpatients with fever, anaemia, or sexually transmitted diseases, and antenatal clinic attenders in Mwanza region, Tanzania? AIDS 1993, 7:567-572.

9. Glynn JR, Buve A, Carael M, Musonda RM, Kahindo M, Macauley I, Tembo F, Zekeng L: Factors influencing the difference in HIV prevalence between antenatal clinic and general population in sub-Saharan Africa. AIDS 200I, I5:1717-I725.

10. Stover J: Projecting the demographic consequences of adult HIV prevalence trends: the Spectrum Projection Package. Sex Transm Infect 2004, 80: I4-18.

II. United Republic of Tanzania: The National Bureau of Statistics. 2002 population and housing census. [http://http.www.tanza nia.go.tz.].

12. Tanzania Commision for AIDS, National Bureau of Statistics and ORC Macro: HIVIAIDS Indicator Survey 2003-2004. 2005.

13. Mnyika KS, Klepp KI, Kvale G, Nilssen S, Kissila PE, Ole-King'ori N: Prevalence of HIV-I infection in urban, semi-urban and rural areas in Arusha region, Tanzania. AIDS 1994, 8: I477-I48I.

14. Killewo J, Dahlgren L, Sandstrom A: A Socio-geographical patterns of HIV-I transmission in Kagera Region, Tanzania. Soc Sci Med 1994, 38:129-134.

15. Mwaluko G, Urassa M, Isingo R, Zaba B, Boerma JT: Trends in HIV and sexual behaviour in a longitudinal study in a rural population in Tanzania, 1994-2000. AIDS 2003, I 7:2645-265I.

16. Barongo LR, Borgdorff MW, Mosha FF, Nicoll A, Grosskurth H, Senkoro KP, Newell JN, Changalucha J, Klokke AH, Killewo JZ: The epidemiology of HIV-I infection in urban areas, roadside settlements and rural villages in Mwanza Region, Tanzania. AIDS 1992, 6: I52I-1528.

17. Bloom SS, Urassa M, Isingo R, Ng'weshemi J, Boerma JT: Community effects on the risk of HIV infection in rural Tanzania. Sex Transm Infect 2002, 78:26I-266.

18. Lugalla J, Emmelin M, Mutembei A, Sima M, Kwesigabo G, Killewo J, Dahlgren L: Social, cultural and sexual behavioral determinants of observed decline in HIV infection trends: lessons from the Kagera Region, Tanzania. Soc Sci Med 2004, 59:185-198.

19. Crosby RA, Kamb ML, Newman D, Zenilman J, Douglas JD, latesta M: Frequency and predictors of condom use and reasons for not using condoms among low-income women. J Sex Edu Therapy 1999, 24:63-70. 
20. Boerma JT, Urassa M, Nnko S, Ng'weshemi J, Isingo R, Zaba B, Mwaluko G: Sociodemographic context of the AIDS epidemic in a rural area in Tanzania with a focus on people's mobility and marriage. Sex Transm Infect 2002, 78:97-105.

21. Bloom SS, Urassa M, Isingo R, Ng'weshemi J, Boerma JT: Community effects on the risk of HIV infection in rural Tanzania. Sex Transm Infect 2002, 78:26I-266.

22. Barongo LR, Borgdorff MW, Mosha FF, Nicoll A, Grosskurth H, Senkoro KP, Newell JN, Changalucha J, Klokke AH, Killewo JZ: The epidemiology of HIV-I infection in urban areas, roadside settlements and rural villages in Mwanza Region, Tanzania. AIDS 1992, 6:|52I-I528.

\section{Pre-publication history}

The pre-publication history for this paper can be accessed here:

http://www.biomedcentral.com/1471-2458/6/120/pre pub

Publish with Bio Med Central and every scientist can read your work free of charge

"BioMed Central will be the most significant development for disseminating the results of biomedical research in our lifetime. "

Sir Paul Nurse, Cancer Research UK

Your research papers will be:

- available free of charge to the entire biomedical community

- peer reviewed and published immediately upon acceptance

- cited in PubMed and archived on PubMed Central

- yours - you keep the copyright

Submit your manuscript here:

http://www.biomedcentral.com/info/publishing_adv.asp 